\title{
Mild spondyloepiphyseal dysplasia due to COL2A1 mutation with early-onset osteoarthritis
}

INSERM

\section{Source}

INSERM. (1999). Orphanet: an online rare disease and orphan drug data base. Mild spondyloepiphyseal dysplasia due to COL2A1 mutation with early-onset osteoarthritis. ORPHA:93279

Mild spondyloepiphyseal dysplasia due to COL2A1 mutation with early-onset osteoarthritis is a type 2 collagen-related bone disorder characterized by precocious, generalized osteoarthritis (with onset as early as childhood) and mild, dysplastic spinal changes (flattening of vertebrae, irregular endplates and wedge-shaped deformities) resulting in a mildly short trunk. 